and Transport what specific measures they are going to take to improve the usage of seat belts in motor cars. Regrettably, about the only option open to them is the education of the driver. On available evidence it is very doubtful whether such a measure would result in much further improvement in usage.

The power that is held by the few strong opponents to the Seat Belts Bill is considerable. Would it be of any help if local branches of the BMA were to arrange visits by opposing MPs to their local accident and emergency departments and hospital wards? Perhaps if MPs were to see the havoc and human tragedy caused by the folly of not wearing seat belts they would withdraw their opposition.

J G AVERY

Harbury, Warwicks CV33 9HG

\section{Quality not quantity in babies}

SIR,-We were disturbed by the content and general tenor of your leading article, "Quality not quantity in babies" (9 February, p 347).

Firstly, while we are pleased that the perinatal mortality for England and Wales is continuing to fall, you state that they are not very far behind Sweden. But 15 against $\mathbf{9 \cdot 4}$ deaths $/ 1000$ represents at $50 \%$ difference, which should not be described as "not very far behind."

Secondly, in the subsequent paragraph the leader mentions measures campaigned for by obstetricians and paediatricians to improve perinatal care, and you indicated that many have not yet been implemented, thus giving the impression that there have been no improvements in medical care in the perinata field. This is untrue as, despite financia restrictions, there have been distinct improvements in perinatal care-for example, increasing emphasis on the active managemen of preterm labour and the management of the babies subsequent to delivery. Also the increased use of ultrasound in the antenatal period has enabled obstetricians to detect abnormalities in fetal growth; while screening -for example, of $\alpha$-fetoprotein levels in Western Scotland-has led to a significant reduction in the number of infants born with spina bifida.

In our own hospital, which is in an area of extreme socioeconomic deprivation, despite an increasing number of infants of low birth weight who had been referred to us before delivery we have managed to achieve a marked drop in perinatal death rates in the period 1975-9 (from 28.5 to $16 \cdot 3$ ), during which time the number of infants less than $2.5 \mathrm{~g}$ birth weight has risen from $6.6 \%$ to $7.9 \%$. This improvement has been achieved by increased co-operation between all those involved in the perinatal period.

We fully support the concept of a perinatal mortality inquiry and in fact have been attempting this in our own region by a continuing analysis of perinatal deaths, using a modification of the WHO perinatal death certificate. We would recommend that other areas introduce this certificate to assess it usefulness and, where appropriate, make modifications or amendments as a preliminary step to a confidential perinatal mortality inquiry.

The incidence of handicap in those of extreme low birth weight (that is, less than $1 \mathrm{~g}$ ) has diminished over the past decade ${ }^{2}$-from $60 \%$ to less than $20 \%$ in more recent surveys.
The rate for handicap also is much lower for those infants whe are born in hospital than for those born outside hospital, ${ }^{3}$ and therefore with the increasing tendency for mothers with high-risk pregnancies to be transferred, if possible before or if not during labour, the incidence of handicap should continue to drop. Furthermore, the more accurate and precise measurement of neonatal heart rate and its significance, ${ }^{4}$ and the closer control of arterial oxygen levels, with transcutaneous and indwelling oxygen electrodes, should reduce the periods of both hypoxaemia and hyperoxia, and thus consequently morbidity. The incidence of a $20 \%$ handicap rate in survivors of assisted ventilation quoted in the leading article should be seen in the context of results from other series, ${ }^{5}$ particularly as regards the method of respiratory assistance-for example, mask continuous positive airway pressure against tube ventilation.

Finally, to compare infants of low birth weight with those with severe spina bifida is to us a totally false parallel. The latter are born with neurological damage and at best this can only be ameliorated, whereas those infants with low birth weight are in most cases born with full potential for intact survival. If we supply only limited care to these small infants there is no guarantee that the ones with limited survival potential will succumb and those with higher potential survive. As Gamsu and his colleagues ${ }^{6}$ have described, the $3 \%$ incidence of severe handicap found in the follow-up of very-low-birthweight infants receiving intensive care is also in keeping with the diminished rates of cerebral palsy, seen in both Sweden ${ }^{7}$ and Western Australia. ${ }^{8}$ These results therefore should give rise to optimism rather than guarded pessimism.

MARK REID

H L HALLIDAY J JENKENS

Royal Maternity Hospital,

Belfast BT12 6BB

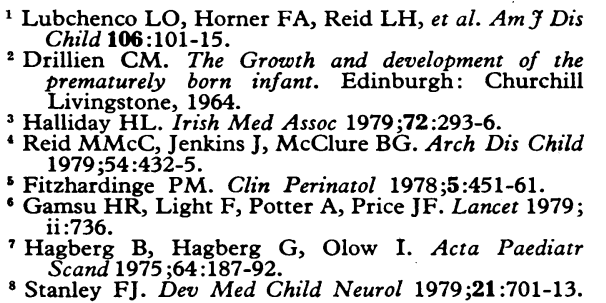

8 Stanley FJ. Dev Med Child Neurol 1979;21:701-13.

SIR,-Few paediatricians and obstetricians can have got much satisfaction from your leading article "Quality not quantity in babies" (9 February, $p$ 347). You imply that the reason for the fall in the perinatal mortality rate is unknown. The assumption seems to have crept into the literature that because one central neonatal unit can show little improvement in the survival of selected babies over 15 years $^{1}$ improved perinatal care counts for nought. May I make the obvious suggestion that the better figures are produced largely by improved levels of perinatal care particularly in peripheral hospitals.

You state that few neonatal intensive care units have been built. Again the assumption is that therefore neonatal units probably have not contributed to the improved figures. Certainly on paper there are few new intensive care units, but in practice nowadays most special care baby units with over 2000 deliveries a year boast one or more intensive care cots. These are often managed by a skeleton staff of nurses and doctors, who nevertheless practice genuine neonatal intensive care. They are not recognised as intensive care cots by National Health Service statistics. Of course not. Recognition might entitle them to adequate funds or sufficient staff. These facilities reflect the interest shown by obstetricians and paediatricians and influence the entire structure of perinatal services.

The same lack of statistical information probably applies to the equipment for neonatal units. On paper very little money has been provided, but most equipment is donated (six out of 10 major items in East Berkshire recently).

You state that all mothers in preterm labour should be transferred to a unit with intensive care facilities, presumably a regional centre. This statement is probably based on two studies that show that very ill babies transferred to a main centre do worse than less ill babies born there. ${ }^{2}$. The idea of transfer sounds good but undoubtedly regional units could not cope with the extra work load, and the effect on parents, often from lower socioeconomic groups, needs more study. Moreover, the winding down of smaller units will render them less safe when an emergency occurs. The controversy may be resolved by randomised trials.

This letter is not only intended to encourage doctors working in peripheral centres in perinatal care. The most important aspect of the continued denigration of the benefits of this work is that the organisers of these services will believe that improved perinatal care makes no difference. Administrators already counter requests for neonatal equipment by saying that better neonatal care has not proved its worth or that premature babies should be transferred to regional centres anyway. I can only refer them to your opening paragraph. How sad that we are having to catch up with mortality figures from France or that four to five more babies per 1000 die in England than in Sweden every year.

\section{JoHn L PeARCe}

Heatherwood Hospital,

Ascot, Berks, and

Canadian Red Cross Memorial Hospital,
Taplow, Bucks

${ }^{1}$ Jones RAK, Cummins M, Davies PA. Lancet 1979 i:1332-5.

Merenstein GB, Pettett G, Woodall J, Hill JM. $A m \mathcal{f}$ Obstet Gynecol 1977;128:520-5. Blake AM, Pollitzer MJ, Reynolds EOR. Br Med $\mathcal{f}$
1979;2:414-6.

SIR,-Your leading article ( 9 February, p 347) states that the fall in perinatal mortality rate may be related to the availability of abortion and by implication to a reduction in illegitimate births. In fact, as the paper by $\mathrm{Mr}$ T L T Lewis (2 February, p 295) shows, although the absolute number of births fell from 610000 in 1975 to 602000 in 1978 , the percentage of illegitimate births rose from $8.8 \%$ to $10 \cdot 2 \%$. Furthermore, in the Merseyside Region the perinatal mortality rate fell from $18 \cdot 7$ per 1000 in 1977 to $15 \cdot 2$ per 1000 in 1978 , while the illegitimacy rate rose from $10.6 \%$ to $11 \%$.

M O LOBB H R ELLIOTT

University Department of Obstetrics and Gynaecology, Liverpool Hospital, 